\title{
AS REPRESENTAÇÕES SOCIAIS DO ALUNO DA EAD SOBRE 0 ENSINO A DISTÂNCIA E EMPREGABILIDADE
}

\author{
Elizza Santana e Silva Barreto* \\ Danielle Ribeiro de Meneses* \\ Daniela Campos Bahia Moscon ${ }^{* *+}$
}

\begin{abstract}
RESUMO: Esta pesquisa traz contribuições às discussões que já vêm sendo realizadas no campo de estudos da educação a distância e empregabilidade e oferece dados para melhor compreensão das representações sociais de alunos ingressantes nessa modalidade. Nesse sentido, o objetivo geral desse estudo é analisar as representações sociais dos alunos do ensino a distância sobre a modalidade e a empregabilidade. Os dados foram coletados por meio de uma entrevista estruturada com alunos de instituições a distância privadas de Salvador, Bahia e, posteriormente, foram analisadas as palavras mais recorrentes; assim como uma análise de conteúdo e da centralidade das características do ensino a distância nas representações sociais. Foi possível concluir que: 1) existe uma representação social positiva da modalidade, o que reforça o fato dela encontrar-se em ascensão; 2) a visão negativa não se sobrepõe aos benefícios, como a flexibilidade; 3) há transformação na representação social do ensino a distância à medida que 0 indivíduo se insere na modalidade; 4) a modalidade e 0 conhecimento construído ao longo da formação são a "chave" para conseguir conquistar satisfação profissional e pessoal, inserir-se no mercado, manter-se empregado e, consequentemente, ter retorno financeiro.
\end{abstract}

PALAVRAS-CHAVE: Ensino a distância; Empregabilidade; Representações sociais.

\section{SOCIAL REPRESENTATIONS OF DE STUDENTS ON DISTANCE EDUCATION AND THE POSSIBILITY OF EMPLOYMENT}

\begin{abstract}
Current research discusses Distance Education and the possibility of employment. It also forwards data for a better understanding of the social representations of studies involved in this educational mode. The social representations of DE students on the educational modality and employment are analyzed. Data were retrieved from interviews with students of DE in private institutions of Salvador, Brazil, and an analysis of the most recurring terms, content analysis and the centrality of the characteristics of $D E$ in social representations was undertaken. Results show that (1) there is a positive social representation of the modality, evidenced by high underscoring; (2) the negative vision does not overshadow benefits, such as flexibility; (3) there is a transformation in the social representation of DE in proportion to student's insertion; (4) modality and knowledge during formation is the key for professional and personal satisfaction, one's insertion in the labor market, employment and financial returns.
\end{abstract}

KEYWORDS: Distance Education; Possibility of employment; Social representations.

\section{INTRODUÇÃO}

Em meio a uma série de mudanças pelas quais o mundo contemporâneo vem passando, a educação a distância - EaD - surge como um meio de estimular e disseminar 0 conhecimento, trazendo for- mas de lidar com espaço e tempo diferentes daqueles definidos pela educação tradicional (FORMIGA, 2009). Nesse sentido, de acordo com França, Matta e Alves (2012), a EaD tem como objetivo principal eliminar as barreiras impostas pela distância física e tornar mais fácil 0 acesso do aluno à informação.

\footnotetext{
Discente de Psicologia na Universidade Salvador (UNIFACS), Salvador (BA), Brasil. E-mail: elizza_sb@hotmail.com

** Discente de Psicologia na Universidade Salvador (UNIFACS), Salvador (BA), Brasil

*** Doutora em Administração pela Universidade Federal da Bahia (UFBA), Docente na na Universidade Salvador (UNIFACS), Salvador (BA), Brasil.
} 
A educação a distância pode ser definida como uma modalidade de ensino que ocorre predominantemente com alunos e professores fisicamente separados na maior parte do tempo e que utiliza de recursos tecnológicos como a internet e o computador para facilitar a comunicação e 0 aprendizado dos alunos, de forma flexível e autônoma (FRANÇA; MATTA; ALVES, 2012).

É importante salientar que não se trata de uma modalidade contemporânea e que não se limita às novas tecnologias de informação e comunicação. Há décadas, a EaD era realizada, por exemplo, por meio de correspondência, telefone, fax, rádio e televisão. Os primeiros registros dessa modalidade de ensino remontam ao século XIX, quando o conteúdo a ser aprendido pelo aluno chegava por meio de correspondências entregues via correio (SANTANA, 2013).

Entretanto, a disseminação de novas tecnologias de informação e comunicação, as NTIC, 0 aumento da acessibilidade à internet e a rápida circulação de informações são fatores que ajudaram na sua disseminação e fazem com que a educação a distância seja vista por algumas pessoas como a "educação do futuro". Dessa forma há a possibilidade de 0 aluno ter um ensino mais flexível, dando-Ihe a oportunidade de ter um aprendizado independente, podendo fazer uma combinação de estudo e trabalho, se este for o caso, sendo assim um sujeito ativo em sua formação. Além disso, haverá menor custo financeiro para 0 estudante, diferenciando-se do ensino presencial, em que os horários são fixos, a frequência é contabilizada pela presença do aluno em sala, os gastos com a mensalidade são maiores, além da relação face-a-face entre aluno e professor.

No contexto brasileiro, a EaD teve origem há mais de um século, no Rio de Janeiro, pouco antes de 1900, por meio de anúncios em jornais de circulação, que ofereciam cursos de datilografia por correspondência. Entretanto, no princípio houve desvalorização do público à modalidade, uma vez que os cursos ainda não eram regulamentados (FRANÇA; MATTA; ALVES, 2012).

A partir da Nova Lei de Diretrizes e Bases da Educação Nacional, lei n. 9394 aprovada em 20 de dezembro de 1996, os cursos foram regulamentados no Brasil, o que colocou a educação a distância como modalidade regular integrante do sistema educacional nacional (SANTOS et al., 2013). Aos poucos foi se desenvolvendo e trilhando sua história no contexto da educação por meio da evolução dos meios de comunicação, até chegar à atualidade, mediada pela tecnologia da internet.

Entre 2011 e 2012, a educação a distância (EaD) cresceu mais que a educação presencial. Houve aumento de 12,2\% nas matrículas da EaD em um ano, enquanto na educação presencial 0 aumento foi de 3,1\% (INEP, 2013). Além disso, um estudo feito a partir dos resultados do ENADE, entre os anos de 2005 e 2006, que comparou o desempenho de alunos nas duas modalidades e apontou, segundo Vianney (2008, p. 6), que "o desempenho dos alunos matriculados nos primeiros semestres de cursos de graduação a distância foi superior em nove de 13 áreas avaliadas" e, quando comparadas às notas obtidas de alunos concluintes, 0 desempenho dos alunos a distância foi superior em sete das 13 áreas submetidas aos exames (VIANNEY, 2008).

Deve-se destacar ainda, que a educação a distância é recheada de benefícios, uma vez que atende a uma população numerosa, mesmo que geograficamente dispersa, oferecendo oportunidades de formação adequadas às exigências atuais daqueles que não puderam iniciar ou concluir sua formação anteriormente. Por ser um modelo flexível, elimina os rígidos requisitos de espaço, tempo e de ritmo comuns no modelo de educação presencial, permitindo eficaz combinação de estudo e trabalho, a fim de garantir a permanência do aluno em seu próprio contexto profissional, cultural e familiar (CAMPOS, 2000).

Além disso, pode-se perceber como mais um benefício da modalidade 0 desenvolvimento da autonomia ao longo do curso. Tal autonomia é indispensável para o futuro desse aluno, uma vez que ao sair da faculdade ele vai se deparar com um mercado de trabalho competitivo e a independência que foi exercitada por ele durante seu percurso na graduação pode ser um grande diferencial na hora de ser contratado e ao executar sua função no futuro emprego. 
0 aluno EaD possui diferencial em relação ao aluno da modalidade presencial quanto ao tempo, que é mais flexível e permite maior contato com o mercado e disponibilidade para participação de programas de estágios, bolsas e treinamentos (trainees) (SANTANA, 2013) e assim contribui para a empregabilidade dos seus estudantes. 0 constructo de empregabilidade surgiu a partir dos programas de preparação para conquista de emprego, em que os educadores buscavam os fatores que iriam contribuir para que seus alunos conseguissem um lugar específico no mercado de trabalho. Hoje, a empregabilidade não mais é entendida apenas como as habilidades necessárias para uma profissão, mas como a junção das competências e das variáveis psicológicas necessárias para conquistar e manter um emprego (CAMPOS, 2011).

0 conceito de competência, segundo Borba et al. (2011), era associado à linguagem jurídica. No entanto, atualmente, a palavra é utilizada para caracterizar algo dinâmico, concretizado no desempenho. Nesse sentido, 0 autor traz que competência seria 0 conjunto dos seguintes elementos: 1) conhecimento: saber, ou seja, buscar constantemente aprender e reaprender; 2) habilidade: saber fazer, ou seja, usar o conhecimento para resolver problemas com criatividade; 3) atitude: saber ser e agir, fazer acontecer. Desta maneira, para exposição de uma competência é presumido que o indivíduo conheça princípios e técnicas específicos, adotando um comportamento no trabalho que exige não apenas conhecimentos, mas também habilidades e atitudes adequadas às necessidades daquele cargo (BORBA et al., 2011).

Dessa forma, empregabilidade refere-se a uma fase de preparo em que o indivíduo, após conseguir um emprego ou trabalho, mostra suas competências, de modo a se manter empregado ou ingressar em outra instituição (CAMPOS, 2011). Assim, o egresso de um curso em EaD pode desenvolver para 0 mercado de trabalho determinadas características muito interessantes a certas áreas de atuação, tais como maior poder de organização, maior disciplina e senso de responsabilidade, capacidade de planejamento e organização do tempo e a familiaridade com a utilização das tecnologias, especialmente na área da informação.

Entretanto, apesar de tamanho desenvolvimento da modalidade, quando se fala em educação a distância ainda é possível perceber um discurso estigmatizado quanto à sua qualidade. Tal estigma vem de tempos atrás, quando era difícil imaginar uma educação que acontecesse longe de uma sala de aula, sem um professor presente fisicamente e com encontros esporádicos. Essa ideia ainda leva as pessoas, em especial os alunos, a terem uma representação social pouco valorizada do ensino a distância, mesmo com 0 seu exponencial crescimento na sociedade.

Essa "representação social" é bastante trazida por Moscovici em diversas de suas obras. Ele a conceitua como um conjunto de opiniões, crenças ou valores que são construídos na relação social e na apropriação das informações, sendo esta tanto individual, quanto grupal, e que auxiliam em uma tomada de decisão. Dada a sua criação, essas ideias se movimentam por entre as outras de forma peculiar, o que possibilita a propagação de umas no meio social e 0 desaparecimento da produção e reprodução de outras (MOSCOVICI, 1978).

A forma como se percebe um objeto, neste caso 0 ensino a distância, pode influenciar no comportamento acerca dele. Assim, representações negativas enraizadas sobre a modalidade podem levar os estudantes a terem medo do futuro profissional, de não conseguirem um emprego ou de serem menosprezados no trabalho. Por outro lado, as organizações podem evitar a entrada dessas pessoas no mercado, por entenderem que elas não são tão qualificadas quanto as que têm uma formação presencial, gerando, dessa forma, toda uma resistência da população e impedindo que ela cresça profissionalmente.

Além disso, os contratantes do setor privado generalizam a EaD, inferindo que esta modalidade não possui uma qualidade de formação de seus alunos, justificados por dados passados ou por escolas não certificadas e oportunistas. A credibilidade do aluno egresso da EaD surgiu principalmente para o mercado contemporâneo com a certificação por universidades 
que lideram a lista mundial das melhores universidades (SANTANA, 2013).

Nesse sentido, percebe-se que a disseminação de uma representação social negativa do ensino a distância pode influenciar na decisão dos alunos de se matricular em um curso dessa modalidade, fazendo com que esta, na maioria das vezes, seja colocada em um patamar inferior em relação à presencial e assim as pessoas que querem ter acesso à educação, seja ela superior ou não, correm o risco de acabar na desistência, ocasionando baixa nas expectativas para 0 futuro, inclusive de crescimento profissional.

0 estudo das representações sociais da educação superior a distância no Brasil pode, portanto, trazer elementos para compreender como grupos distintos de alunos optaram pela modalidade a distância ou presencial, sobre como "utilizaram as representações sociais para definir identidades e estabelecer relações de proximidade ou de distanciamento com a educação a distância, e, com isso, guiar e justificar comportamentos e práticas"' (VIANNEY, 2006, p. 33).

Uma vez que os estudantes da $\mathrm{EaD}$ são os protagonistas desta prática e que o modo como eles a enxergam pode influenciar na sua relação com 0 curso, sua autoestima e na confiança no desenvolvimento de estratégias para melhorar sua empregabilidade, faz-se então necessário analisar as representações sociais dos alunos do ensino a distância sobre a EaD e a empregabilidade, sendo esse 0 objetivo geral desse estudo.

Para atender a esse objetivo geral, faz-se necessário desdobrá-lo em alguns objetivos específicos, tais como: 1) identificar conceitos que os alunos EaD têm sobre essa modalidade; 2) compreender 0 que vem a ser empregabilidade para os alunos EaD; 3) verificar qual a visão que os alunos EaD têm do mercado de trabalho e do futuro profissional; 4) analisar 0 quanto os alunos EaD entendem que essa modalidade pode influenciar na sua inserção no mercado de trabalho. Mesmo com as diferenças, o pensamento socialmente construído deve ser reconhecido e levado à tona, principalmente no âmbito educacional, podendo desta forma contribuir para a ressignificação de paradigmas e do processo pedagógico oferecido aos discentes.

\section{METODOLOGIA}

Esse estudo foi desenvolvido com base em uma pesquisa com abordagem quali-quantitativa, exploratória e descritiva. A amostra contém 26 sujeitos, sendo 16 do sexo feminino e 10 do sexo masculino, com idades que variam entre 16 e 50 anos. Trata-se de estudantes de cursos da modalidade de educação à distância, sendo doze do curso de Administração, dez do curso de Ciências Contábeis e quatro de Pedagogia, como mostra a Tabela 1.

Tabela 1. Caracterização da amostra

\begin{tabular}{lc}
\hline Variáveis & $\mathbf{n = 2 6}$ \\
\hline Gênero & 16 \\
\hline Feminino & 10 \\
Masculino & \\
\hline Idade & 2 \\
\hline De 16 a 23 anos & 9 \\
De 24 a 30 anos & 14 \\
De 31 a 40 anos & 1 \\
De 41 a 50 anos & \\
\hline Curso & 12 \\
\hline Administração & 10 \\
Ciências Contábeis & \\
Pedagogia & \\
\hline
\end{tabular}

Fonte: Elaboração própria

No que se refere ao período da graduação, os entrevistados encontram-se entre o meio do curso e a sua conclusão. Além disso, observa-se que possuem experiência profissional em suas áreas de formação, tendo uma média de cinco anos e mediana de três no mercado de trabalho, embora a maioria da amostra 
afirme nunca ter participado de cursos ou orientações sobre como buscar emprego. Vale ressaltar que o perfil padrão de alunos dos cursos a distância no Brasil está mudando. Anteriormente, os alunos eram mais maduros e já tinham alguma formação. Hoje, um público mais jovem entra em cena, sendo em sua maioria mulheres, que trabalham e têm entre 18 e 30 anos (ASSOCIAÇÃO BRASILEIRA DE EDUCAÇÃO A DISTÂNCIA, 2013).

0 estudo foi desenvolvido a partir de uma entrevista estruturada, contendo 12 itens, predominantemente abertos, que buscaram compreender quais são as representações sociais dos alunos EaD sobre a educação a distância e empregabilidade. A sua aplicação foi feita presencialmente com os alunos EaD de duas faculdades privadas da cidade de Salvador, Bahia, mediante concordância do Termo de Consentimento Livre e Esclarecido.

Nos estudos de representação social é muito comum usar questionários e entrevistas para inferir as representações, pois essas estratégias podem possibilitar a apreensão dos conteúdos e dos sentidos do objeto de pesquisa por meio dos seus elementos constitutivos (ALVES-MAZZOTTI, 2008).

Após a coleta de dados, foram analisadas quais as palavras mais recorrentes nas respostas das questões $6,7,8,11$ e 12, tanto em termos de ordem de evocação, quanto de frequência, possibilitando compreender o núcleo central e periférico das representações dessa população através da ferramenta Wordle, que permite criar uma nuvem de palavras a partir de um texto. Além disso, foi analisado o conteúdo, das respostas das questões 9 e 10.

Essa técnica de análise verifica o que foi dito na entrevista, buscando classificar esse conteúdo em categorias que vão auxiliar na compreensão do que está por trás do discurso dos respondentes (SILVA; FOSSÁ, 2015). A análise de conteúdo alcançou popularidade a partir de Bardin (1977), que ressalta a importância do rigor na utilização da técnica, a fim de ultrapassar as incertezas e descobrir o que é questionado.

Por ser uma técnica refinada, o pesquisador necessita ter disciplina, dedicação e paciência (SIL-
VA; FOSSÁ, 2015). Existem alguns passos na análise de conteúdo do material coletado, Bardin (1977) as elenca em três fases: 1) pré-análise, 2) exploração do material e 3) tratamento dos resultados, inferência e interpretação. Na primeira fase, faz-se uma leitura geral dos dados, enquanto na segunda codificam-se as informações, formulando categorias de análise. Posteriormente, faz-se um recorte do material em parágrafos comparáveis e com 0 mesmo conteúdo semântico, assim estabelecem-se categorias com temas diferenciados, transpondo os dados brutos para dados organizados. Após agrupar os parágrafos em categorias comuns e de forma progressiva, entra-se na última fase, em que é realizada a interpretação dos dados, que deverá ser respaldada no referencial teórico.

Por fim, para maior compreensão do fenômeno investigado neste estudo, foi utilizada a ferramenta Mapa de Dispersão Espacial, que fornece, por meio de uma projeção visual, a relação existente entre duas ou mais variáveis. 0 grau de centralidade do mapa é obtido a partir da combinação de dois aspectos: primeiro, a ordem das características escolhidas, onde se considera que as primeiras escolhas são consideradas as mais importantes já que estão mais salientes e mais significativamente representadas nas estruturas de conhecimento dos indivíduos. Segundo, considera-se a frequência com que cada característica é escolhida, o que determina o quanto ela é difundida e compartilhada entre os membros de um grupo ou de uma organização (MOSCON, 2009).

Destaca-se, ainda, que o estudo qualitativo acerca das representações sociais, segundo Souza (2009), é relevante para o desenvolvimento de uma pesquisa que objetiva identificar e compreender por meio das experiências cotidianas o significado dos comportamentos e relações entre as pessoas e objetos dentro de um contexto social e de um sistema de crenças e ideias que vão guiando as suas escolhas e atitudes.

Por fim, vale ressaltar que esse estudo ocorreu conforme a aprovação do Comitê de Ética em 
Pesquisa, a partir das orientações da Plataforma Brasil acerca dos cuidados na pesquisa com seres humanos.

\section{RESULTADOS E DISCUSSÕES}

Nessa sessão serão apresentados os resultados provenientes das entrevistas realizadas, por meio de uma análise descritiva e de conteúdo. Primeiramente, é importante ressaltar que os resultados aqui elencados não necessariamente refletem 0 universo pesquisado, uma vez que a amostra possui um número pequeno de respondentes.

Outro ponto importante são os objetivos específicos desse estudo, que foram transformados em quatro dimensões: 1) conceitos que os alunos da $\mathrm{EaD}$ têm sobre a modalidade; 2) 0 que vem a ser empregabilidade para os alunos EaD; 3) a visão que os alunos EaD têm do mercado de trabalho e do futuro profissional; 4) influência da modalidade na inserção e/ou permanência dos alunos EaD no mercado de trabalho.

Quanto à dimensão da visão que os alunos têm acerca da sua modalidade, quando questionados sobre suas percepções antes de ingressarem, muitos se limitaram a responder "nada", "pouco" ou que sabiam que 0 ensino era "flexível" e "reconhecido pelo MEC", como visto na Figura 1, gerada através da ferramenta Wordle.

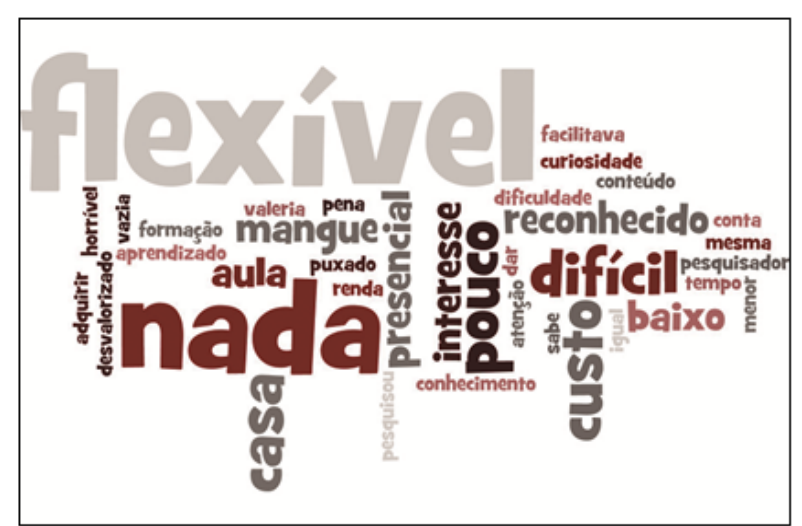

Figura 1. Visão dos estudantes sobre a EaD antes de serem ingressos nessa modalidade Fonte: Elaboração própria

Além disso, essa visão pode também ser observada a partir de exemplos extraídos dos próprios depoimentos dos participantes quando dizem: "eu sabia pouco, achava que 0 EAD era igual ao presencial, só que com custo e tempo reduzido e era flexível para ter aulas em casa".

Por outro lado, oito alunos trouxeram um discurso negativo acerca da modalidade, pois pensavam que ela era "horrível", "mangue" (expressão baiana que significa desorganizado, bagunçado, confuso), "difícil", apesar de a terem escolhido. Isso possibilita inferir que possíveis vantagens, talvez advindas do menor custo e flexibilidade, possam se sobrepujar às representações sociais negativas acerca da modalidade no momento da escolha. Essa inferência corrobora com a afirmação de Campos (2000), quando diz que $0 \mathrm{EaD}$, por ser um modelo flexível, elimina os rígidos requisitos de espaço, tempo e de ritmo comuns no modelo de educação presencial, permitindo eficaz combinação de estudo e trabalho, garantindo a permanência do aluno em seu próprio contexto profissional, cultural e família.

Em contrapartida, quando são perguntados sobre 0 que pensam acerca do conceito da modalidade a distância, uma vez que agora já estão inseridos nela, muitos dos respondentes não conseguiram citar as cinco palavras requeridas pela questão, alegando que não sabiam ou que nunca tinham pensado a respeito, 0 que pode indicar que os alunos podem refletir pouco acerca das suas escolhas, mesmo depois de terem experienciado mais da metade do seu curso superior.

Nesse sentido, as palavras mais frequentes e evocadas nessa dimensão, como pode ser visto na Figura 2, foram "dificuldade", "flexibilidade", "reconhecimento", "tempo" e "comodidade", o que aparenta significar que os alunos encontram dificuldades de gerenciar o seu próprio estudo, uma vez que não tem auxílio do tutor o tempo inteiro e muitas vezes precisam conciliar o curso com 0 trabalho, realidade comum entre os entrevistados. Por outro lado, os alunos continuam concordando que a flexibilidade é um fator positivo da modalidade, o que facilita a aquisição de um diploma, mais tempo para experiências práticas ao longo da formação, ou em paralelo a ela, 
e um futuro reconhecimento profissional. Esse dado corrobora com Santana (2013), quando afirma que 0 aluno EaD tem um diferencial em relação ao aluno da modalidade presencial, pois possui um tempo flexível para estar em contato com o mercado e a disponibilidade para participar de programas de estágios, bolsas e treinamentos (trainee).

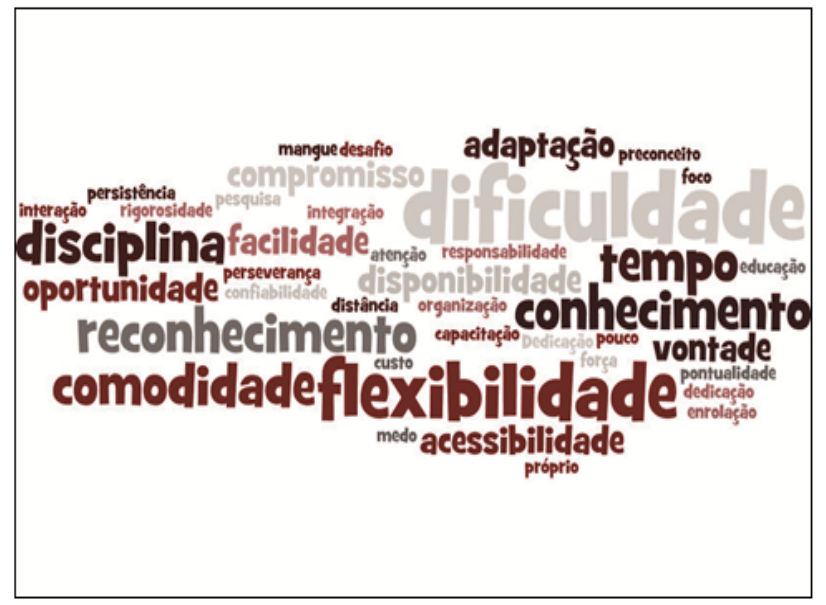

Figura 2. Três primeiras palavras que vinham à mente dos estudantes EaD quando pensavam em ensino a distância Fonte: Elaboração própria

Já no que diz respeito à dimensão que trata da compreensão do aluno EaD acerca do conceito de empregabilidade, as palavras mais recorrentes, como pode ser visto na Figura 3, foram "conhecimento", "dificuldade", "compromisso", "profissionalização", "formação" e "concorrência". Com isso, percebe-se que para esses alunos o conhecimento, que foi a palavra mais recorrente dentre todas, é o ponto de partida para manter-se empregado, considerando que a empregabilidade se refere a uma fase de preparo do indivíduo para 0 ingresso e permanência no mercado de trabalho, assim como a junção das competências e das variáveis psicológicas necessárias (CAMPOS, 2011).

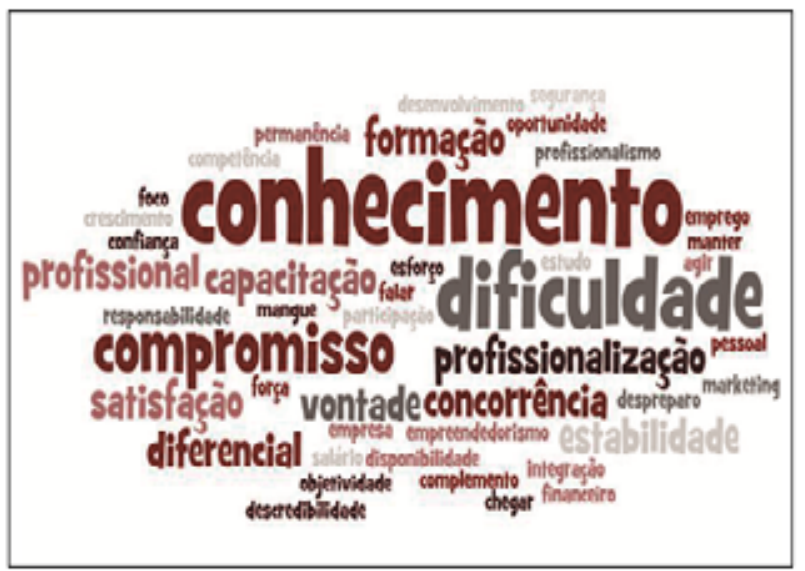

Figura 3. Três primeiras palavras que vinham à mente dos estudantes EaD quando pensavam em empregabilidade Fonte: Produção própria

Desta forma, percebe-se que esses alunos focam sua atenção para a busca do conhecimento, uma vez que muitos já estão inseridos no contexto profissional, possivelmente já possuindo as habilidades e atitudes necessárias para 0 cargo que exercem, mas ainda sentem a necessidade de ir a busca do conhecimento requerido pelo mercado de trabalho para que assim consigam atender às demandas sociais, como ter um diploma de formação para ser considerado um profissional capacitado. Essa inferência pode ser corroborada pela fala de um dos entrevistados, quando diz: "acredito que através do conhecimento, da obtenção do diploma, a minha experiência na área será validada". Além disso, vale ressaltar que os alunos da modalidade EaD apresentam, segundo Vianney (2008), um desempenho superior aos alunos presenciais quando submetidos a testes como 0 ENADE (Exame Nacional de Desempenho dos Estudantes).

Também no que se refere à dimensão da visão que os alunos da modalidade de educação a distância têm do mercado de trabalho e do seu futuro profissional, percebe-se um discurso oriundo de estudantes que, em sua maioria, já se encontram inseridos no contexto profissional. Nesse sentido, por meio das entrevistas, foi possível destacar uma visão de um mercado amplo e ao mesmo tempo competitivo e desleal, o que aparenta estimulá-los a buscar mais capacitação na sua área, uma vez que ainda acredi- 
tam que sem o diploma de formação será mais difícil permanecer e se desenvolver dentro do mercado de trabalho.

Desta forma, os alunos da modalidade à distância se capacitam, pois, acreditam que por intermédio do conhecimento construído ao longo do curso conseguirão adquirir estabilidade financeira e sucesso, que são suas maiores expectativas em relação ao futuro profissional, como se pode perceber através Figura 4.

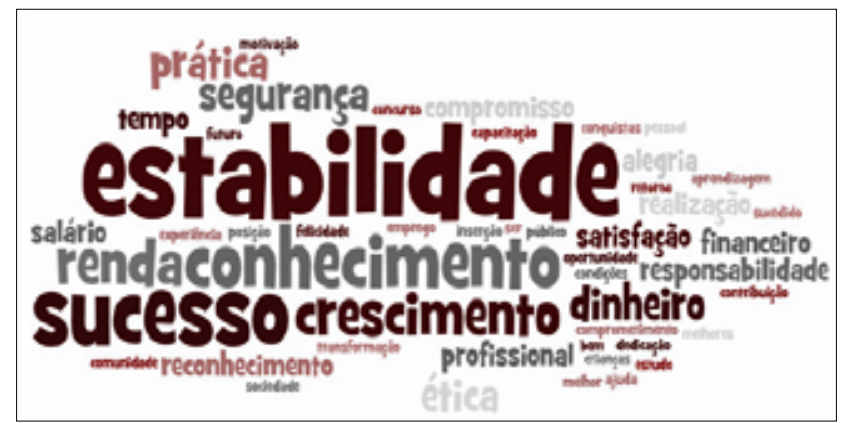

Figura 4. Visão do estudante EaD acerca do mercado de trabalho atual na sua área Fonte: Elaboração própria
0 mesmo ocorre quando se analisa a dimensão da visão que os alunos têm acerca da modalidade a distância e do modo como ela pode influenciar na sua inserção e/ou permanência no mercado de trabaIho, já que mais uma vez a palavra conhecimento é a que tem a maior frequência de evocação. Desta forma, o ensino a distância é visto como uma chave, uma porta para a construção do conhecimento e aquisição de um diploma necessário e tão cobrado pelo contexto profissional, mas em um tempo reduzido, comparado ao ensino tradicional.

Por fim, para maior compreensão do fenômeno, foi utilizada a ferramenta Mapa de Dispersão Espacial, bastante presente nos estudos de representações sociais. Para tanto, foi construído um glossário com as palavras mais recorrentes trazidas pelos entrevistados que foram agrupadas e transformadas em 12 categorias, sendo elas: competências, satisfação, integração, responsabilidade, dificuldade, retorno financeiro, mercado, flexibilidade, conhecimento, credibilidade, descrédito e currículo.

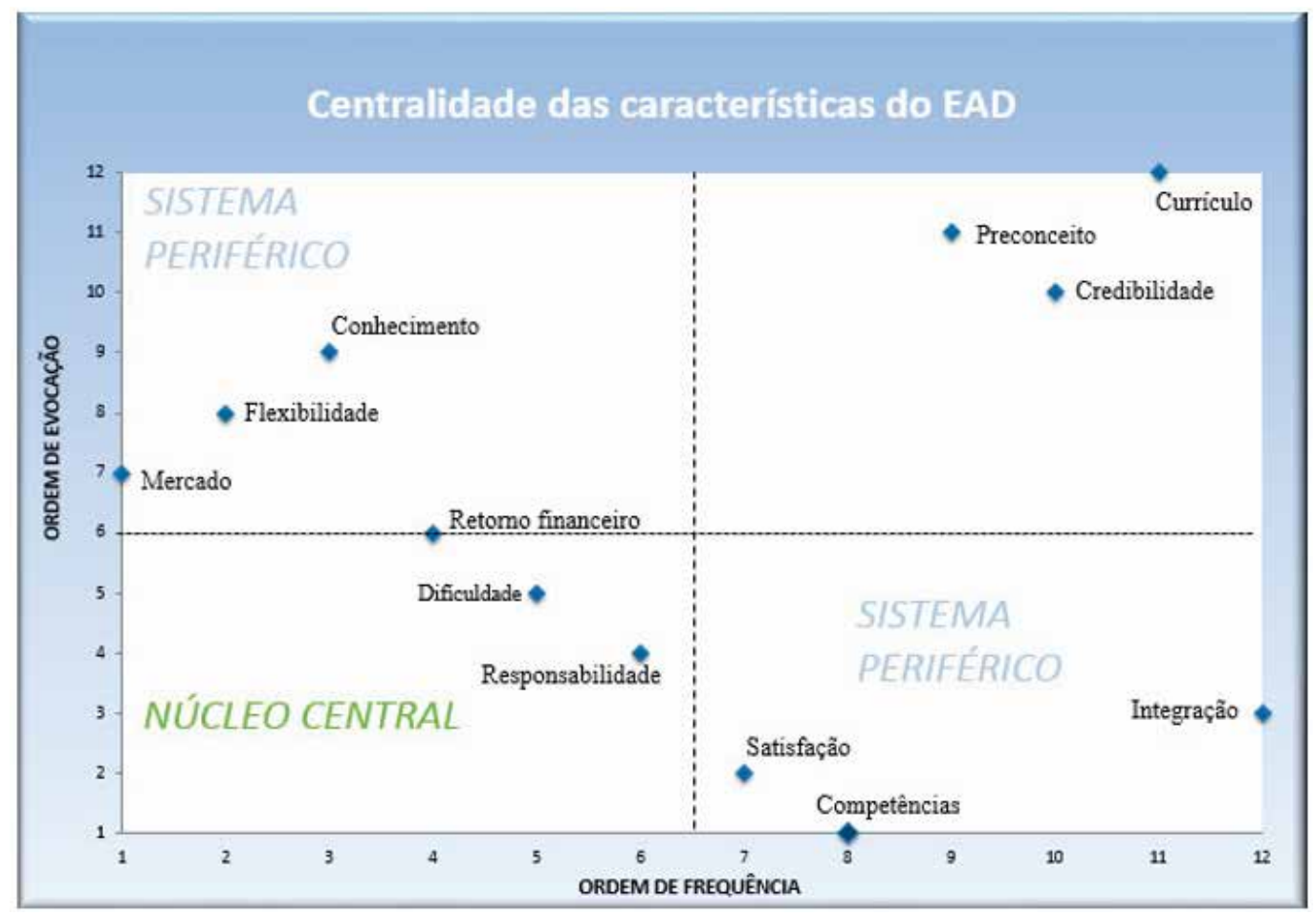

Figura 5. Centralidade das características do EaD Fonte: Elaboração própria 
A apresentação dos resultados foi feita na forma de mapa de dispersão espacial das características consideradas mais centrais e mais periféricas, como apresentado na Figura 5.

A análise do mapa, segundo Moscon (2009), é realizada a partir da dispersão espacial que é feita pela distribuição em três grandes áreas: núcleo central, núcleo periférico e categorias residuais. 0 núcleo central é composto pelas características que foram escolhidas como as mais importantes (primeiras na ordem de escolha) e mais compartilhadas (mais escolhidas) pelo grupo de participantes e compõe a parte inferior esquerda do mapa (MOSCON, 2009). Nesse sentido, percebe-se que quando questionados a respeito da sua modalidade e da empregabilidade, os alunos EaD trazem em seu discurso palavras ligadas a "responsabilidade" e "dificuldade", referentes à sua modalidade de ensino, e que remete uma possível transformação quanto à representação social do ensino à distância, que antes era pontuada como sendo "fácil" ou algo que não demanda dedicação.

Assim, pode-se dizer que essa dificuldade pode estar relacionada com diversos fatores, como ao próprio modelo de ensino que é diferente do tradicional e que possivelmente é uma nova experiência para esse ingresso; aos recursos tecnológicos, que podem ter problemas técnicos ou até mesmo a falta de habilidade do aluno com o sistema (AVA); à dificuldade de conciliar 0 trabalho com 0 estudo, já que a maioria da amostra está inserida no mercado de trabalho; e, por fim, a própria flexibilidade, característica da modalidade, que faz com que 0 fator responsabilidade seja interligado ao da dificuldade, pois além dela ser primordial para obtenção do conhecimento, torna 0 aluno mais autônomo durante a graduação e consequentemente no mercado de trabalho. Desta forma por "ser difícil" 0 aluno precisará ser responsável para enfrentar as dificuldades que surgem durante a graduação.

Quanto aos sistemas periféricos, são compostos pelas características consideradas menos importantes (últimas na ordem de escolha), porém bastante citadas pelos participantes ou, pelo contrário, embora sejam pouco compartilhadas pelos entrevistados, foram consideradas importantes por aqueles que a escolheram. Compõem a parte inferior direita e a superior esquerda do mapa (MOSCON, 2009).

Analisando os sistemas periféricos, percebe-se que categorias como "retorno financeiro", "mercado" e "satisfação" (pessoal e profissional) encontram-se mais próximas ao núcleo central que as demais. Outra categoria que chama atenção é o fator "flexibilidade", que durante as entrevistas foi sempre relacionado à escolha da modalidade. Referente à categoria "retorno financeiro" muitos acreditam que com a obtenção de um diploma poderão melhorar suas finanças, como também permanecer no mercado de trabalho e, em seguida, galgar novos cargos.

Já as categorias residuais, são aquelas que foram menos citadas e consideradas menos importantes, localizam-se na parte superior direita do mapa (MOSCON, 2009). Categorias como "preconceito", "credibilidade" e "currículo" foram consideradas menos importantes que todas as outras, ao mesmo tempo em que palavras relacionadas ao preconceito contra a modalidade a distância foram pouco evocadas. 0 mesmo ocorre com as palavras que dão crédito a própria modalidade, 0 que significa que enquanto as pessoas policiam seu discurso negativo e preconceituoso quanto ao ensino a distância também não aparentam dar crédito ou qualificá-las. Assim, por serem categorias menos importantes para os respondentes, fica claro que os fatores "credibilidade" e "preconceito" não são impedimento para que escolham a modalidade e permaneçam nela. Isso pode explicar 0 fator crescimento da modalidade no país, uma vez que outros aspectos começaram a ganhar destaque e se sobrepor às representações sociais negativas ao longo dos anos.

Vale ressaltar que algumas palavras foram avaliadas como "resíduo" e não foram consideradas no mapa de dispersão espacial, já que só foram evocadas uma vez durante todas as entrevistas. 


\section{CONCLUSÃO}

Uma das conclusões mais importantes que se pode extrair deste estudo é que ele atende a todos os quatro objetivos específicos, mas ao mesmo tempo traz um resultado surpreendente. Percebe-se uma representação social positiva acerca do EaD, assim como verifica-se que ele está em ascensão, pois a visão negativa não se sobrepõe aos benefícios trazidos por ele, como a flexibilidade. Outrossim, percebe-se uma transformação na representação social do EaD à medida que 0 indivíduo se insere na modalidade, já que antes de serem ingressos, os alunos tinham uma visão da modalidade que se difere da que apresentam atualmente, como, por exemplo, questões como responsabilidade e dificuldade.

0 estudo mostra que a modalidade e 0 conhecimento construído ao longo da formação são a "chave" para conseguir conquistar satisfação profissional e pessoal, se inserir no mercado, manter-se empregado e consequentemente ter retorno financeiro. Além do que, os participantes percebem uma pressão social a respeito da necessidade da aquisição de um diploma, de forma que sem ele não conseguirão se inserir e se manter no mercado de trabalho, quando na realidade 0 que mais importa é a construção do conhecimento a ser aplicado no contexto profissional.

Durante a construção do estudo houve alguns empecilhos que foram, de certa forma, limitadores ao acesso dos participantes, uma vez que nem todas as instituições de educação a distância possuem encontros presenciais, sendo assim difícil acessá-los para aplicar as entrevistas, limitando a amostra. Entretanto, entendeu-se que essa dificuldade não interferiu de forma decisiva nos resultados, uma vez que se observou o critério de exaustão temática, já que as respostas oferecidas apresentaram certa semelhança, o que pode ser considerado como representativo daquele grupo populacional. Porém, é preciso deixar claro, mais uma vez, que os resultados dessa pesquisa não necessariamente refletem 0 universo da educação a distância.

Outro ponto foi a mobilização de um participante ao longo da entrevista, que não conseguia res- ponder às perguntas, pois se deu conta de que nunca tinha parado para pensar no seu futuro profissional e consequentemente na sua formação. Esse ponto da possibilidade de uma possível mobilização foi 0 que determinou que as entrevistas fossem feitas presencialmente, e não on-line como tem sido cada vez mais usual em pesquisas dessa natureza.

Por fim, conclui-se que embora esse estudo tenha cumprido seu objetivo, ainda existem outras formas de análise que, sob outros olhares, poderão contribuir no sentido de compreender o que pensam alunos, tanto da modalidade a distância, quanto presencial, professores ou mesmo líderes em organizações. Esse estudo é apenas o ponto de partida para novas pesquisas, uma vez que se acredita que a temática da educação a distância e da empregabilidade, por estarem em ascensão no país, precisam continuar sendo estudadas, atualizadas e continuamente transformadas para atender às demandas da sociedade contemporânea.

\section{REFERÊNCIAS}

ALVES-MAZZOTTI, A. J. Representações Sociais: Aspectos Teóricos e Aplicações à Educação. Múltiplas Leituras, Brasília, v. 1, n. 1, p.18-43, 2008. Disponível em: <https://www.metodista.br/revistas/revistas-ims/index.php/ML/article/viewFile/1169/1181>. Acesso em: 09 abr. 2014.

ASSOCIAÇÃO BRASILEIRA DE EDUCAÇÃO A DISTÂNCIA. Censo EAD BR: Relatório Analítico da Aprendizagem a Distância no Brasil 2012. Curitiba: Ibpex, 2013. 204p. Disponível em: <http://www.abed.org.br/censoead/ censoEAD.BR_2012_pt.pdf>. Acesso em: 27 jul. 2015.

BARDIN, L. Análise de conteúdo. Lisboa: Edições 70, 1977.

BORBA, J. S. de et al. A definição dos conhecimentos, habilidades e atitudes na formação de administradores na percepção de gestores, acadêmicos e legal. In: CONGRESSO VIRTUAL BRASILEIRO DE ADMINISTRAÇÃ0, 8., 2011, São Paulo. Anais... São Paulo: Instituto Pantex de Pesquisa, 2011. v. 1, p. 1 - 16. Disponível 
em: <http://www.convibra.com.br/upload/paper/adm/ adm_2917.pdf >. Acesso em: 16 jul. 2015.

CAMPOS, G. H. B. de. Pensando a educação a distância. Revista TI, nov. 2000. Disponível em: <http:// www.timaster.com.br/revista/artigos/main_artigo.asp?codigo=253 > . Acesso em: 15 jun. 2014.

CAMPOS, K. C. de L. Construção de uma escala de empregabilidade: definições e variáveis psicológicas. Estudos de Psicologia, Campinas, v. 1, n. 28, p.4555, mar. 2011. Disponível em: < http://www.scielo.br/ pdf/estpsi/v28n1/a05v28n1.pdf>. Acesso em: 15 jun. 2014.

FRANÇA, C. L.; MATTA, K. W. da; ALVES, E. D. Psicologia e educação a distância: uma revisão bibliográfica. Psicol. cienc. prof. [online], v.32, n.1, 2012. Disponível em: <http://www.scielo.br/scielo.php?script=sci_ arttext\&pid=S1414-98932012000100002>. Acesso em: 15 set. 2014.

FORMIGA, M. A terminologia da EAD. In: LITTO, F.; FORMIGA, M (Org.). Educação a distância: 0 estado da arte. São Paulo: Pearson, 2009. p. 39-46.

INSTITUTO NACIONAL DE ESTUDOS E PESQUISAS EDUCACIONAIS. INEP. Brasil teve mais de 7 milhões de matrículas no ano passado. 2013. Disponível em: <http://portal.inep.gov.br/visualizar/-/asset_publisher/6AhJ/content/brasil-teve-mais-de-7-miIhoes-de-matriculas-no-ano-passado>. Acesso em: 15 set. 2014.

MOSCON, D. C. B. Teorias implícitas de trabalhador comprometido e estratégias cotidianas de gestão: uma análise qualitativa. 2009. 135f. Dissertação (Mestrado) - Universidade Federal da Bahia, Salvador, 2009. Disponível em: <http://www.adm.ufba.br/sites/default/files/publicacao/arquivo/dissertacao_versao_final_-_daniela_moscon.pdf $>$. Acesso em: 04 jul. 2015.

MOSCOVICI, S. A Representação social da psicanálise. Rio de Janeiro: Zahar, 1978.

SANTANA, 0. A. Alunos egressos das licenciaturas em EaD (consórcios setentrionais e UAB: 2001-2012), sua empregabilidade e absorção pelo mercado. Revista
Brasileira de Aprendizagem Aberta e A Distância, Recife, p. 48-59, 2013. Disponível em: <http://www. abed.org.br/revistacientifica/_Brazilian/2013/3A_Ar_ tigo_Rbaad_Portugues_2ed.pdf $>$. Acesso em: 06 abr. 2014.

SANTOS, C. K. S.; BRUNO JUNIOR V. B.; LEAL, E.; ALBERTIN, A. L. Propensão dos Estudantes de Ciências Contábeis á Educação a distância. Revista Capital científico, v. 11 n. 3, 2013. Disponível em: <http:// www.ead.fea.usp.br/semead/15semead/resultado/ trabalhosPDF/296.pdf>. Acesso em: 08 abr. 2014.

SILVA, A. H.; FOSSÁ, M. I. T. Análise de Conteúdo: Exemplo de Aplicação da Técnica Para Análise de Dados Qualitativos. Qualit@s, Paraíba, v. 17, n. 1, p.114, 2015. Disponível em: <http://revista.uepb.edu.br/ index.php/qualitas/article/view/2113/1403>. Acesso em: 23 out. 2016.

SOUZA, R. C. As representações sociais dos professores e alunos sobre a relação ensino e aprendizagem em educação a distância na UNITINS. 2009. 154f. Dissertação (Mestrado em Educação) - Universidade de Brasília, Brasília, 2009. Disponível em: <http:// repositorio.unb.br/bitstream/10482/4861/1/2009_ RaquelCastilhoSouza.pdf>. Acesso em: 09 abr. 2014.

VIANNEY, J. As representações sociais da educação a distância: uma investigação junto a alunos do ensino superior a distância e a alunos do ensino superior presencial. 2006. 329f. Tese (Doutorado Interdisciplinar em Ciências Humanas) - Universidade Federal de Santa Catarina, 2006. Disponível em: < http://livros01. livrosgratis.com.br/cp109599.pdf>. Acesso em: 09 abr. 2014.

VIANNEY, J. A ameaça de um modelo único para a EaD no Brasil. Colabor@ - Revista Digital da CVA-RICESU, set. 2008. Disponível em: <http://pead.ucpel.tche. br/revistas/index.php/colabora/article/viewFile/2/2>. Acesso em: 23 jul. 2014.

Recebido em: 16 de junho de 2016 Aceito em: 01 de novembro de 2016 